\title{
Multimorbidity, control and treatment of non- communicable diseases among primary healthcare attenders in the Western Cape, South Africa
}

\author{
N Folb, ${ }^{1,2,3}$ MB ChB, MRCGP (UK); V Timmerman, ${ }^{1}$ PhD; N S Levitt, ${ }^{2,3}$ MB ChB, MD, FCP (SA); K Steyn ${ }^{2,3}$ MSc, NED, MD; \\ M O Bachmann, ${ }^{4} \mathrm{MB} \mathrm{ChB}, \mathrm{PhD}, \mathrm{FFPH}(\mathrm{UK})$; C Lund, ${ }^{5} \mathrm{MA}$, MSocSci, PhD; E D Bateman, ${ }^{1,2,3} \mathrm{MB}$ ChB, MD, FRCP (UK); \\ C Lombard ${ }^{3,6,7}$ MSc, PhD; T A Gaziano, ${ }^{3,8}$ MD, MSc; M Zwarenstein, ${ }^{9}$ MB ChB, MSc, PhD; L R Fairall, ${ }^{1,2,3}$ MB ChB, PhD \\ ${ }^{1}$ University of Cape Town Lung Institute, Cape Town, South Africa \\ ${ }^{2}$ Department of Medicine, Faculty of Health Sciences, University of Cape Town, South Africa \\ ${ }^{3}$ Chronic Disease Initiative for Africa, Department of Medicine, Faculty of Health Sciences, University of Cape Town, South Africa \\ ${ }^{4}$ Norwich Medical School, University of East Anglia, Norwich, UK \\ ${ }^{5}$ Alan J Flisher Centre for Public Mental Health, Department of Psychiatry and Mental Health, Faculty of Health Sciences, \\ University of Cape Town, South Africa \\ ${ }^{6}$ Biostatistics Unit, Medical Research Council, Cape Town, South Africa \\ ${ }^{7}$ School of Public Health and Family Medicine, Faculty of Health Sciences, University of Cape Town, South Africa \\ ${ }^{8}$ Cardiovascular Medicine, Brigham \& Women's Hospital, Boston, MA, USA \\ ${ }^{9}$ Centre for Studies in Family Medicine, Department of Family Medicine, Schulich School of Medicine and Dentistry, \\ Western University, London, ON, Canada
}

Corresponding author: N Folb (naomi.folb@uct.ac.za)

Background. South Africa (SA) is facing a heavy burden of non-communicable diseases (NCDs). Few studies address multimorbidity, control and treatment of NCDs in patients attending primary healthcare (PHC) clinics.

Objectives. To describe multimorbidity, related risk factors, disease severity and treatment status of patients with four important NCDs attending public sector PHC clinics in two districts in SA.

Methods. A cross-sectional sample of patients completed baseline data collection for a randomised controlled trial of a health systems intervention. The study population comprised adults attending PHC clinics in the Eden and Overberg districts of the Western Cape in 2011. Four subgroups of patients were identified: hypertension, diabetes, chronic respiratory disease and depression. A total of 4393 participants enrolled from 38 clinics completed a baseline structured questionnaire and had measurements taken. Prescription data were recorded. Results. Of participants with hypertension, diabetes, respiratory disease and depression, $80 \%, 92 \%, 88 \%$ and $80 \%$, respectively, had at least one of the other three conditions. There were low levels of control and treatment: $59 \%$ of participants with hypertension had a blood pressure $\geq 140 / 90 \mathrm{mmHg}$, the mean haemoglobin A1c (HbAlc) value in participants with diabetes was $9 \%, 12 \%$ of participants in the depression group were prescribed an antidepressant at a therapeutic dose, and $48 \%$ of respiratory participants were prescribed a $\beta_{2}$-agonist and $34 \%$ an inhaled corticosteroid.

Conclusion. Considerable multimorbidity and unmet treatment needs exist among patients with NCDs attending public sector PHC clinics. Improved strategies are required for diagnosing and managing NCDs in this sector.

S Afr Med J 2015;105(8):642-647. DOI:10.7196/SAMJnew.7882

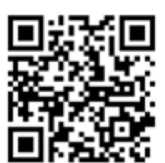

South Africa (SA) faces a rise in non-communicable diseases (NCDs) in both rural and urban populations, driven by an increase in risk factors such as tobacco use, physical inactivity and unhealthy diets. ${ }^{[1]}$ These place a heavy burden on public sector primary healthcare (PHC) services. A recent cross-sectional survey of reasons for consultations in PHC in four SA provinces confirmed that management of hypertension was the most common reason for attendance, with NCDs accounting for $14 \%$ of visits. ${ }^{[2,3]}$

$\mathrm{PHC}$ in the public sector is nurse-led with support from doctors, with nurses seeing over $85 \%$ of all patients. ${ }^{[2]}$ However, at present nurses working at PHC clinics often do not have the necessary skills or capacity to deal adequately with NCDs. ${ }^{[1]}$ Chronic diseases and risk factors are often undiagnosed and inadequately treated, resulting in high levels of poor control and morbidity. ${ }^{[1,4-6]}$

There is renewed focus on NCD care in SA. However, despite the magnitude of the NCD burden, there are few recent studies addressing multimorbidity, control and treatment of NCDs in this country. In particular, little is known about the multimorbidity of depression with other NCDs.

We present an analysis of the clinical characteristics, level of disease control, presence of multimorbidity and treatment of patients with hypertension, diabetes, chronic respiratory disease and symptoms of depression, identified in PHC clinics in the Eden and Overberg districts of the Western Cape Province, SA, as part of the Primary Care 101 trial described below.

\section{Methods}

This study describes the characteristics of patients participating in the Primary Care 101 trial at enrolment. The Primary Care 101 programme comprised a customised clinical practice guideline and training programme aimed at assisting healthcare providers, largely nurses, with the primary care management of adults. The pragmatic cluster randomised controlled trial evaluated the effects of the 
programme on the quality and outcomes of care for hypertension, diabetes, chronic respiratory disease and depression. Clinics were randomised either to receive the intervention or not. The main results of the trial will be published elsewhere.

The 33 largest clinics in the Eden district that provided NCD care, and a convenience sample of five clinics in the neighbouring Overberg district, were included in the study. Each clinic had at least 10000 attendances per year and was staffed by nurse practitioners, doctors, and community health workers who manage clinic patients in the communities. These clinics are the main providers of PHC for local populations with high levels of unemployment and socioeconomic deprivation.

Eligible participants were clinic attenders aged 18 years or older, likely to reside in the area for the next year, and able to engage in an interviewer-administered questionnaire. Patients attending each clinic were interviewed to assess their eligibility for inclusion in the hypertension, diabetes, chronic respiratory and/or depression groups, until the sample size required for each group was reached. For the hypertension and diabetes groups, a self-reported history of medication use for these conditions was required. For the respiratory group, a self-report of prescription of medications for chronic respiratory disease or symptoms of chronic respiratory disease (cough or difficult breathing for $>2$ weeks), ${ }^{[7]}$ and no current or recent treatment for tuberculosis, was required. The depression group comprised participants with a score of $\geq 10$ on the 10-item Center for Epidemiologic Studies Depression Scale (CESD-10). ${ }^{[8]}$ Individuals could be included in more than one group. In this article 'comorbidity' refers to two coexisting conditions and 'multimorbidity' to three or more coexisting conditions.

For trial purposes the sample sizes for each disease group were calculated separately, and were 27 participants per clinic for the chronic respiratory disease group and 60 per clinic for each of the other three groups. These target sample sizes were attained or exceeded for all disease groups except the diabetes group, which reached 48 participants per clinic.

Fieldworkers invited patients attending the trial clinics to be screened for inclusion in the study using a structured questionnaire. Eligible patients who provided informed consent were enrolled and completed another, baseline, questionnaire. Between March and October 2011, 4904 patients were screened, of whom 4393 were enrolled. The questionnaire was available in Afrikaans, isiXhosa and English. It included questions relating to demographic characteristics, socioeconomic factors, medical history and smoking status. Three blood pressure (BP) readings were taken at least 2 minutes apart with an Omron automatic monitor. The first reading was excluded and the values from the second and third readings were averaged. ${ }^{\left[{ }^{[]}\right.}$Height, weight and waist circumference were measured using standardised techniques. Height and weight were measured with participants barefoot and wearing light clothing. A flexible tape was used to measure waist circumference, $2.5 \mathrm{~cm}$ above the umbilicus. Haemoglobin Alc (HbAlc) was measured only in 20 randomly selected clinics because of cost and logistical constraints. Diabetic participants in the 20 clinics were referred to a clinic nurse at the end of the interview for an HbAlc test, which was processed by the National Health Laboratory Service.

The severity of respiratory disease was assessed with the Symptom and Activity domains of the St Georges Respiratory Questionnaire $(\mathrm{SGRQ})^{[10]}$ in participants enrolled in the respiratory disease group. Scores are expressed as percentages, with $100 \%$ representing worst and $0 \%$ best possible health status. The presence of symptoms of depression was assessed with the CESD-10 scale, which was administered to all participants enrolled in the study. ${ }^{[8]}$ The items were scored from 0 (rarely or none of the time) to 3 (most of the time).

Treatment for depression was defined as having received counselling or been referred to psychiatric services within the past year, or currently receiving an antidepressant. Counselling was defined as a consultation that intended to seek solutions to problems or provide emotional support, and not simply give advice on medication use. Participants who reported receiving counselling from a mental health nurse, clinic counsellor, social worker, psychiatrist or psychologist were considered to have received counselling, and those who reported receiving counselling from a mental health nurse, psychiatrist or psychologist were considered to have been referred to psychiatric services.

Chronic medication prescribed to participants at the time of their interview for depression, hypertension, diabetes and respiratory disease was recorded. Fieldworkers photocopied all available prescription charts for the year preceding the interview. The trial manager (NF) examined the prescription charts of each participant to identify medications prescribed at the time of their interview. A data capturer entered the prescription data (drug names, doses and frequencies) into an access database, and a total daily dose for each drug was calculated. Prescription charts were available for $99.3 \%$ of participants.

Quality control measures included supervision of fieldworkers, electronic alert messages for fieldworkers who entered unusually high or low values, and regular monitoring of the data to identify unusual values or trends. Quality control checks performed on the capturing of prescription data included double entry and checking all unusually high or low doses and frequencies.

The trial was registered with Current Controlled Trials (ISRCTN20283604) and the Office for Human Research Protections Database. Ethical approval was obtained from the University of Cape Town Human Research Ethics Committee and the Western Cape Provincial Department of Health. Participants provided written informed consent for their interview and prescription data to be collected and analysed. All data were anonymised for analysis, and participant identities were revealed only to the fieldworker and a limited number of researchers who received and prepared the data for analysis.

\section{Results}

Thirty-eight clinics were included in the study. The median number of nurses per clinic was four. Forty per cent of clinics had daily doctor support, the remainder had sessional support from doctors, and $42 \%$ of clinics had an on-site pharmacy.

A total of 4393 participants were enrolled into the study, of whom $73 \%$ were women. The median age was 52 years, and $73 \%$ had hypertension, $42 \%$ diabetes, $26 \%$ chronic respiratory disease and $56 \%$ a CESD-10 score of $\geq 10$ and so could be considered to be at risk of depression.

The majority of the participants (84\%) were Afrikaans speaking, $75 \%$ were unemployed, $7 \%$ had never attended school, and $42 \%$ had achieved high-school education. Fifty-eight per cent reported receiving a social welfare grant, including $44 \%$ of participants under the age of 60 years. The median income in the month prior to the interview date was ZAR1 140, including personal non-grant income plus any household grant that benefited the participant, such as a disability or child grant.

Although $31 \%$ of participants were current smokers, their median pack-year history was only 7.5. Twenty-five per cent of participants provided a history of cardiovascular disease (heart attack, angina or stroke), $11 \%$ had a history of tuberculosis (TB), $2 \%$ reported 
being on medication for TB at the time of the interview, and $2 \%$ reported being on antiretroviral drugs.

The NCD-related health characteristics of participants in each of the four disease groups are presented in Table 1.

In the hypertension group (3 227 participants), $59 \%$ had a BP $\geq 140 / 90 \mathrm{mmHg}$ and $10 \%$ had a $\mathrm{BP} \geq 180 / 110 \mathrm{mmHg}$, indicating poor control. Their mean body mass index $\left(\mathrm{BMI}, \mathrm{kg} / \mathrm{m}^{2}\right.$ ) was $31,27 \%$ were current smokers, and $26 \%$ reported a history of cardiovascular disease. Of the 1166 participants not in the hypertension group, 25\% had a $B P \geq 140 / 90 \mathrm{mmHg}$ and were not on medication for hypertension.

The diabetes group comprised 1842 participants, of whom 704 had their $\mathrm{HbAlc}$ measured. The mean HbAlc value was $9.1 \%$ and $77 \%$ had an HbAlc above the target of 7\%, indicating poor glycaemic control. The mean BMI for all participants with diabetes was $32,23 \%$ were current smokers, and $23 \%$ reported a history of cardiovascular disease. An elevated BP $(\geq 140 / 80 \mathrm{mmHg})^{[11]}$ was present in $77 \%$, and $8 \%$ had a BP $\geq 180 / 110 \mathrm{mmHg}$.

The chronic respiratory disease group comprised 1157 participants, of whom $50 \%$ reported being on medication for respiratory disease and 50\% were identified by symptoms alone. Eighteen per cent had a previous history of TB and 39\% were current smokers. Their median pack-year history was 7.5. The median symptom and activity domain scores of the SGRQ were 60 and 74 , respectively.

The depression group comprised a total of 2466 participants. Their median CESD10 score was 14 (interquartile range (IQR) 12 - 18).

Of participants with hypertension, diabetes, respiratory disease and depression, $80 \%, 92 \%, 88 \%$ and $80 \%$, respectively, had at least one of the other three conditions, and $34 \%, 45 \%, 53 \%$ and $42 \%$ had at least two other conditions (Fig. 1). Hypertension was the commonest comorbidity in participants with other categories of chronic disease, followed by depression, diabetes and chronic respiratory disease. Forty-seven per cent of participants in the hypertension group also had diabetes, $84 \%$ of participants with diabetes also had hypertension, $22 \%$ of participants with hypertension or diabetes also had chronic respiratory disease, and 51\% of participants with hypertension, diabetes or respiratory disease had a CESD-10 score of $\geq 10$.

Treatment received by participants in the hypertension group at the time of their interview is presented in Table 2. Four per

Table 1. Characteristics of study participants

\begin{tabular}{|c|c|}
\hline Hypertension group & $\begin{array}{l}\text { All participants } \\
(N=3227)\end{array}$ \\
\hline Systolic BP (mmHg), mean (SD) ( $n=3220)$ & $139(23.6)$ \\
\hline Diastolic BP (mmHg), mean (SD) ( $n=3220)$ & $90(13.2)$ \\
\hline $\mathrm{BP} \geq 140 / 90 \mathrm{mmHg}, n(\%)$ & $1917(59.4)$ \\
\hline $\mathrm{BP} \geq 180 / 110 \mathrm{mmHg}, n(\%)$ & $334(10.4)$ \\
\hline BMI $\left(\mathrm{kg} / \mathrm{m}^{2}\right)$, mean $(\mathrm{SD})(n=3066)$ & $31.1(7.5)$ \\
\hline BMI, proportion obese (BMI $\geq 30), n(\%)$ & $1628(50.5)$ \\
\hline Waist circumference $(\mathrm{cm})$, mean (SD) $(n=3$ 194) & $100.5(15.6)$ \\
\hline Waist circumference $(\mathrm{cm})$, proportion greater than ideal, ${ }^{\star} n(\%)$ & $2293(71.1)$ \\
\hline Current smokers, $n(\%)$ & $885(27.4)$ \\
\hline Pack-year history for current smokers, median (IQR) $(n=756)$ & $8(4.8-13.8)$ \\
\hline Cardiovascular disease, ${ }^{\dagger} n(\%)$ & $849(26.3)$ \\
\hline Diabetes group & $\begin{array}{l}\text { All participants } \\
(N=1 \text { 842) }\end{array}$ \\
\hline HbAlc $(\%),{ }^{\ddagger}$ mean $(\mathrm{SD})(n=704)$ & $9.1(2.5)$ \\
\hline Proportion $\mathrm{HbAlc} \geq 7 \%, n(\%)$ & $544 / 704(77.3)$ \\
\hline SBP $(\mathrm{mmHg})$, mean (SD) $(n=1840)$ & $137(23.2)$ \\
\hline DBP $(\mathrm{mmHg})$, mean $(\mathrm{SD})(n=1840)$ & $88(12.4)$ \\
\hline $\mathrm{BP} \geq 140 / 80 \mathrm{mmHg}, n(\%)$ & $1414(76.8)$ \\
\hline $\mathrm{BP} \geq 180 / 110 \mathrm{mmHg}, n(\%)$ & $139(7.5)$ \\
\hline BMI, mean (SD) ( $n=1742)$ & $32.0(7.3)$ \\
\hline BMI, proportion obese (BMI $\geq 30), n(\%)$ & $1011(54.9)$ \\
\hline Waist circumference, mean (SD) $(n=1822)$ & $103.6(14.8)$ \\
\hline Waist circumference, proportion greater than ideal, ${ }^{\star} n(\%)$ & $1436 / 1842(78.0)$ \\
\hline Current smokers, $n(\%)$ & $415(22.5)$ \\
\hline Pack-year history for current smokers, median (IQR) $(n=353)$ & $8.25(4.8-16.0)$ \\
\hline Cardiovascular disease, ${ }^{\dagger} n(\%)$ & $423(23.0)$ \\
\hline Chronic respiratory disease group & $\begin{array}{l}\text { All participants } \\
(N=1157)\end{array}$ \\
\hline Self-reported CRD on respiratory medication, $n(\%)$ & $699(60.4)$ \\
\hline Self-reported CRD symptoms and not on respiratory medication, $n$ (\%) & $458(39.6)$ \\
\hline SGRQ symptom domain (\% maximum weight), median (IQR) ( $n=833)$ & $59.50(36.4-74.8)$ \\
\hline SGRQ activity domain (\% maximum weight), median (IQR) ( $n=1054)$ & $73.71(53.6-92.5)$ \\
\hline Current smokers, $n(\%)$ & $454(39.2)$ \\
\hline Pack-year history for current smokers, median (IQR) & $7.8(4.4-13.5)$ \\
\hline Previous tuberculosis, $n$ (\%) & $211(18.2)$ \\
\hline Depression group & $\begin{array}{l}\text { All participants } \\
(N=2466)\end{array}$ \\
\hline CESD-10 score, mean (SD); median (IQR) & $15.3(4.3) ; 14(12-18)$ \\
\hline Current smokers, $n(\%)$ & $860(34.9)$ \\
\hline Pack-year history for current smokers, median (IQR) $(n=754)$ & $7.2(3.9-13.5)$ \\
\hline
\end{tabular}

cent of participants in the hypertension group had no evidence of having received antihypertensive medication, $14 \%$ were on one antihypertensive agent, and $15 \%$ were on three or more antihypertensive drugs at optimal dosages. Fifty-five per cent of participants with hypertension were prescribed aspirin and $34 \%$ a statin. 


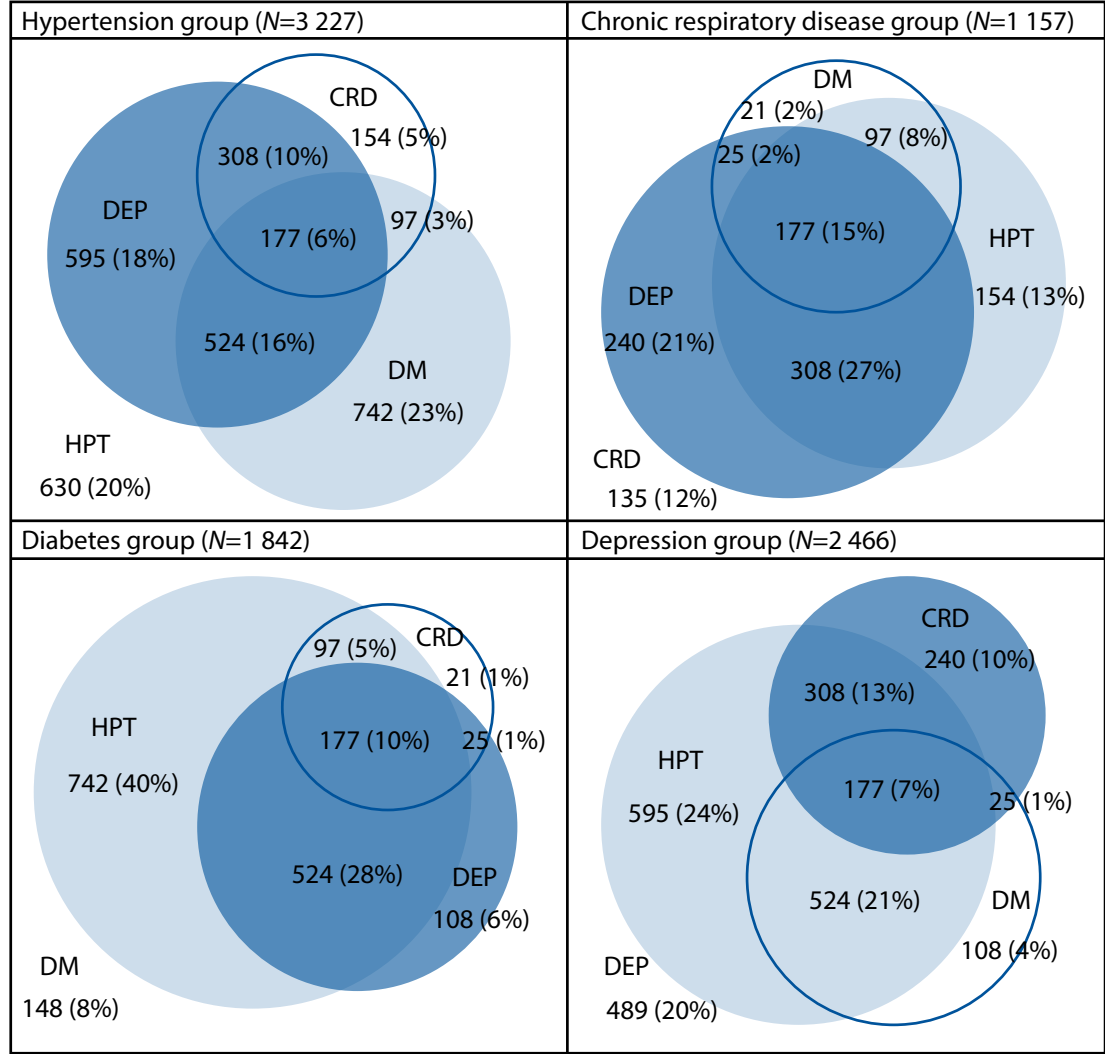

Fig. 1. Venn diagram of multimorbidity associated with hypertension, diabetes, chronic respiratory disease and depression. $(H P T=$ hypertension; $D M=$ diabetes; $C R D=$ chronic respiratory disease; $D E P=$ depression.)

Table 2. Treatment, hypertension group

\begin{tabular}{|c|c|c|c|}
\hline Medications prescribed & $\begin{array}{l}\text { All participants } \\
(N=3227) \\
n(\%)\end{array}$ & $\begin{array}{l}\text { Controlled } \\
\mathrm{BP}^{\star+}(N=1303) \\
n(\%)\end{array}$ & $\begin{array}{l}\text { Uncontrolled } \\
\mathrm{BP}^{\ddagger \dagger}(N=1917) \\
n(\%)\end{array}$ \\
\hline \multicolumn{4}{|l|}{ Hypertension medications } \\
\hline No hypertension medication & $129(4.0)$ & $80(62.0)$ & $47(36.4)$ \\
\hline 1 hypertension medication & $436(13.5)$ & $207(47.5)$ & $229(52.5)$ \\
\hline$\geq 2$ hypertension medications & $2638(81.7)$ & $1003(38.0)$ & $1631(61.8)$ \\
\hline $\begin{array}{l}\geq 3 \text { antihypertensive } \\
\text { medications at optimal dosage }\end{array}$ & $482(14.9)$ & $140(29.0)$ & $341(70.8)$ \\
\hline Missing information & $24(0.7)$ & & \\
\hline Aspirin & $1760(54.5)$ & $711(40.4)$ & $1047(59.5)$ \\
\hline Statin & $1093(33.9)$ & $445(40.7)$ & $647(59.2)$ \\
\hline \multicolumn{4}{|c|}{$\begin{array}{l}{ }^{*} \mathrm{BP}<140 / 90 \mathrm{mmHg} . \\
{ }^{+} \text {Frequencies and row percentages exclude } 7 \text { participants with missing BP readings. } \\
{ }^{\mathrm{B}} \mathrm{BP} \geq 140 / 90 \mathrm{mmHg} .\end{array}$} \\
\hline
\end{tabular}

Treatment received by participants in the diabetes group is presented in Table 3. Sixtyone per cent of participants with diabetes had been prescribed an oral hypoglycaemic agent (without insulin) and 32\% were prescribed insulin (with or without oral hypoglycaemic agents). Aspirin had been prescribed for $63 \%$ in the diabetes group, and statins for $51 \%$. Seven per cent of participants with diabetes had had no hypoglycaemic agents prescribed. In both the hypertension and diabetes groups, we observed higher medication use in participants with poorer control.

In the respiratory group, $48 \%$ of participants had been prescribed a $\beta_{2}$-agonist metered dose inhaler (MDI) or nebuliser, $34 \%$ an inhaled corticosteroid (any dose), 8\% an ipratropium bromide MDI or nebuliser, and $11 \%$ slow-release theophylline as maintenance treatment (Table 4).
In the depression group, $12 \%$ of participants had been prescribed a therapeutic dose of antidepressant and $10 \%$ a subtherapeutic dose $(<50 \mathrm{mg} / \mathrm{d})$ of amitriptyline or imipramine (Table 5). Twenty-five per cent were receiving treatment for depression, defined as receiving counselling, referral to psychiatric services or being on an antidepressant at a therapeutic dose. Fortyfive per cent were not receiving treatment, and it could not be established whether the remaining $30 \%$ were receiving treatment for depression, either because prescription charts were not available (14 participants) or because the participant failed to answer the question regarding counselling and psychiatric referral (729 participants).

\section{Discussion}

This study described the clinical profile, disease control, multimorbidity and treatment received by patients with the target conditions attending PHC clinics in two districts in SA. The results indicated poor disease control, high levels of multimorbidity and unmet treatment needs in the public sector in these districts.

These findings confirm previous reports of poor control and treatment of NCDs, and demonstrate little improvement in NCD control since these earlier studies were conducted. A study of 1089 patients in 18 community health centres in 1999 demonstrated poor levels of control of hypertension and diabetes in community health centres in the Cape Peninsula, with $67 \%$ of hypertensive patients recording a BP $\geq 140 / 90 \mathrm{mmHg}$ and a mean HbAlc of $8.8 \%$ in diabetic patients. ${ }^{[4]}$ A study of goldminers in Gauteng Province, SA, in $2009 / 2010$ found that only $42 \%$ of patients diagnosed with hypertension received antihypertensive medication, while $69 \%$ of patients on antihypertensive medication were poorly controlled. ${ }^{[12]}$ The South African Stress and Health Study, a community survey of 4351 adult South Africans between 2002 and 2004, found that only one-quarter of patients with depression, anxiety and substance use disorders received treatment. ${ }^{[6]}$ Comorbidity of hypertension and diabetes was found to be high in a cross-sectional study in Cape Town townships in 2008/2009, with $21 \%$ of participants with hypertension also having diabetes, compared with $7 \%$ of non-hypertensive patients having diabetes. ${ }^{[9]}$ The cross-sectional study in the Cape Peninsula in 1999 found 31\% of participants with hypertension to have diabetes and $64 \%$ of participants with diabetes to have hypertension. ${ }^{[4]}$ A more recent survey of SA PHC found that $18 \%$ of patients with 
Table 3. Treatment, diabetes group

\begin{tabular}{|c|c|c|c|c|}
\hline $\begin{array}{l}\text { Medications } \\
\text { prescribed }\end{array}$ & $\begin{array}{l}\text { All participants } \\
(N=1842) \\
n(\%)\end{array}$ & $\begin{array}{l}\text { Subgroup with } \\
\text { HbAlc test }(N=704) \\
n(\%)\end{array}$ & $\begin{array}{l}\text { Controlled } \\
(N=160) \\
n(\%)\end{array}$ & $\begin{array}{l}\text { Uncontrolled } \\
(N=544) \\
n(\%)\end{array}$ \\
\hline \multicolumn{5}{|l|}{$\begin{array}{l}\text { Hypoglycaemic } \\
\text { medications }\end{array}$} \\
\hline $\begin{array}{l}\text { No diabetes } \\
\text { medications }\end{array}$ & $119(6.5)$ & $33(4.7)$ & $23(69.7)$ & $10(30.3)$ \\
\hline $\begin{array}{l}\text { Metformin } \\
\text { and/or } \\
\text { sulfonylurea } \\
\text { (but not } \\
\text { insulin) }\end{array}$ & $1126(61.1)$ & $438(62.2)$ & $112(25.6)$ & $326(74.4)$ \\
\hline $\begin{array}{l}\text { Insulin (with/ } \\
\text { without oral } \\
\text { agents) }\end{array}$ & $588(31.9)$ & $230(32.7)$ & $25(10.9)$ & $205(89.1)$ \\
\hline $\begin{array}{l}\text { Missing } \\
\text { information }\end{array}$ & $9(0.5)$ & & & \\
\hline Aspirin & $1155(62.7)$ & $477(67.8)$ & $101(21.2)$ & $376(78.8)$ \\
\hline Statin & $931(50.5)$ & $407(57.8)$ & $82(20.1)$ & 325 (79.9) \\
\hline ACE inhibitor & $1215(66.0)$ & $475(67.5)$ & $108(22.7)$ & $367(77.3)$ \\
\hline \multicolumn{5}{|c|}{$\begin{array}{l}\text { ACE = angiotensin-converting enzyme. } \\
{ }^{*} \mathrm{HbAlc}<7 \% .\end{array}$} \\
\hline
\end{tabular}

Table 4. Treatment, chronic respiratory disease group

\begin{tabular}{|c|c|c|c|}
\hline Medications prescribed & $\begin{array}{l}\text { All participants } \\
(N=1157) \\
n(\%)\end{array}$ & $\begin{array}{l}\text { SGRQ symptom } \\
\text { domain score } \\
\text { Median (IQR) }\end{array}$ & $\begin{array}{l}\text { SGRQ activity } \\
\text { domain score } \\
\text { Median (IQR) }\end{array}$ \\
\hline $\begin{array}{l}\text { No chronic respiratory disease } \\
\text { medications }\end{array}$ & $567(49.0)$ & $52.6(29.8-68.5)$ & $67.2(47.7-85.8)$ \\
\hline Selective $\beta_{2}$-agonist & $558(48.2)$ & $64.6(44.9-78.9)$ & $79.8(59.5-92.5)$ \\
\hline Inhaled corticosteroids (any dose) & $388(33.5)$ & $64.6(42.8-79.3)$ & $80.3(60.3-92.5)$ \\
\hline Inhaled corticosteroid ( $\geq 800 \mu \mathrm{g} / \mathrm{d})$ & $346(29.9)$ & $64.9(41.8-80.2)$ & $80.4(60.3-92.5)$ \\
\hline Theophylline & $121(10.5)$ & $70.4(51.8-83.0)$ & $79.8(60.4-92.5)$ \\
\hline Ipratropium bromide & $91(7.9)$ & $69.7(52.2-81.6)$ & $85.8(60.4-93.2)$ \\
\hline
\end{tabular}

Table 5. Treatment, depression group

\begin{tabular}{|c|c|c|}
\hline Medications prescribed or other management & $\begin{array}{l}\text { All participants } \\
(N=2466) \\
n(\%)\end{array}$ & $\begin{array}{l}\text { CESD-10 score } \\
\text { Median (IQR) }\end{array}$ \\
\hline \multicolumn{3}{|l|}{ Antidepressant medications } \\
\hline No antidepressant medications & $1902(77.1)$ & $14(12-17)$ \\
\hline Antidepressant at therapeutic dose & $294(11.9)$ & $19(14-22)$ \\
\hline Antidepressant at subtherapeutic dose & $250(10.1)$ & $15(12-19)$ \\
\hline Missing information & $20(0.8)$ & \\
\hline Received counselling in past year & $402(16.3)$ & $15(12-20)$ \\
\hline Psychiatric referral in past year & $175(7.1)$ & $17(13-21)$ \\
\hline $\begin{array}{l}\text { Antidepressant at therapeutic dose or counselling in } \\
\text { past year or psychiatric referral in past year }\end{array}$ & $614(24.9)$ & $16(12-20)$ \\
\hline
\end{tabular}

hypertension also had diabetes, and $63 \%$ tension. ${ }^{[3]}$ Our study demonstrated higher of patients with diabetes also had hyper- levels of comorbidity than these studies, with $47 \%$ of participants with hypertension also having diabetes, and $84 \%$ of participants with diabetes also having hypertension. A study of urban SA women demonstrated high rates of comorbid psychological distress with physical disease, ${ }^{[13]}$ consistent with our finding of $51 \%$ of participants with hypertension, diabetes or chronic respiratory disease also having symptoms of depression. However, the high rates of multimorbidity in our study, particularly in the reporting of diabetes in the hypertension group, may partly be due to the sampling strategy, as explained in 'Study limitations' below.

\section{Study limitations and strengths}

This study had several limitations. It did not consider other potential comorbid conditions such as osteoarthritis which are likely in such patient populations, so multimorbidity and comorbidity were probably underestimated. The study was not intended to provide estimates of the prevalence of NCDs or depression symptoms, but its inclusion criteria may have influenced the interpretation of results. Because the inclusion criteria for each condition involved self-reporting, there was misclassification; some participants' reported diseases were not confirmed, while others were found to be receiving medications for a disease that they had not reported. For example, of 1166 participants not enrolled in the hypertension group (denying receiving medication for this diagnosis), $13 \%$ had received a prescription for antihypertensive medication and $30 \%$ had a BP $\geq 140 / 90 \mathrm{mmHg}$. Further, of 3227 participants who reported being on medication for hypertension, 5\% had no evidence of a prescription for hypertension. The inclusion criterion for the diabetes group was self-reported diabetes medication. Patients with diabetes on dietary control alone were therefore not included in the study. The study's chronic respiratory disease definition was probably more inclusive than usual clinical practice and so may have overestimated disease prevalence. Spirometry was not used to diagnose respiratory disease. We did not distinguish between asthma, chronic obstructive pulmonary disease or other symptomatic chronic lung diseases, and severity was not assessed by lung function tests. For these reasons, the appropriateness of treatments prescribed could not be assessed for individual participants. The study's definition of possible depression indicates, but does not confirm, clinical depression. In addition, the percentage receiving counselling or referral is an 
underestimate owing to an error resulting in this question not being administered to all participants. Finally, the sampling strategy may have led to over-representation of reported comorbidities. For the randomised controlled trial we estimated that 60 patients were needed per clinic for each disease group except for the respiratory group, which required 27 patients per clinic. Owing to the high prevalence of hypertension in this clinic population, targets were easily met for the hypertension group, although it was more difficult to do the same for the diabetes group. Fieldworkers were asked to continue recruitment until targets were met for all four groups, with the result that targets were exceeded for all groups except diabetes, where recruitment fell short $(81 \%$ of target). Since the majority of patients with diabetes also had hypertension, extended recruitment of this group may have led to an over-representation of the proportion of those with hypertension who also had diabetes.

The study had a number of strengths. The sample size was large, data were collected for four disease groups, and prescription data were collected for $99 \%$ of participants. There are few other recent studies addressing multimorbidity, control and treatment of NCDs in public sector PHC clinics in SA.

\section{Conclusion}

The rising prevalence of NCDs is a major challenge facing healthcare systems worldwide, with multimorbidity becoming the norm for people with chronic diseases. Despite this, health systems tend to be configured for individual diseases. ${ }^{[14]}$ The high levels of multimorbidity demonstrated in this study stress the need for PHC services to provide better-integrated NCD care. Clinicians need to consider potential coexistence of, and interactions between, diseases. Training of clinicians to manage multimorbidity is essential, and should address both appropriateness of prescribing and adherence to medication. Management of NCDs and multimorbidity need to be addressed at a health systems level and factored into clinical training. The Integrated Chronic Disease Management ${ }^{[15]}$ and Primary Care $101^{[16]}$ programmes are important current initiatives aimed at integrating chronic disease care and addressing multimorbidity. After a decade of focusing on scaling up antiretroviral therapy programmes, management of NCDs in PHC needs to be prioritised and requires similar investment in order to improve outcomes and limit the impact on morbidity and mortality. With limited time and resources in the PHC setting, careful consideration of how to prioritise care is required.

Understanding the causes of poor NCD control will assist in prioritising care and resources. Further research is required into the development and evaluation of interventions to address the burden and unmet treatment needs of NCDs, including mental health.

Funding. This project has been funded in part with Federal funds by the United States National Heart, Lung, and Blood Institute, National Institutes of Health, Department of Health and Human Services, under Contract No. HHSN268200900030C. Funding was also received from United Health, USA; the Department of Health of the Provincial Government of the Western Cape; the Department of Medicine, University of Cape Town; the UK Department for International Development; and the University of Cape Town Lung Institute. The study sponsors did not contribute to the design of the study, to the collection, analysis and interpretation of data, or to the writing of this article or the decision to submit it for publication. The researchers were independent from funders and sponsors, and researchers involved in the collection, analysis and interpretation of the data had access to all the data.

Acknowledgements. The authors thank all clinic nurses, doctors, managers, pharmacists and pharmacy assistants at participating study facilities; the Department of Health of the Provincial Government of the Western Cape; the Eden and Overberg district management; Primary Care 101 trainers and fieldworkers; and the National Health Laboratory Service.

\section{References}

1. Mayosi BM, Flisher AJ, Lalloo UG, Sitas F, Tollman SM, Bradshaw D. The burden of noncommunicable diseases in South Africa. Lancet 2009;374(9693):934-947. [http://dx.doi.org/10.1016/ S0140-6736(09)61087-4]

2. Mash B, Fairall L, Adejayan O, et al. A morbidity survey of South African primary care. PLoS One 2012;7(3):e32358. [http://dx.doi.org/10.1371/journal.pone.0032358]

3. Lalkhen H, Mash R. Comorbidity and multimorbidity in non-communicable diseases in South African primary healthcare. S Afr Med J 2015;105(2):134-138. [http://dx.doi.org/10.7196/SAMJ.8696]

primary healthcare. S Afr Med J 2015;105(2):134-138. [http://dx.doi.org/10.7196/SAMJ.8696]
4. Steyn K, Levitt NS, Patel M, et al. Hypertension and diabetes: Poor care for patients at community 4. Steyn K, Levitt NS, Patel M, et al. Hypertension
health centres. S Afr Med J 2008;98(8):618-622.

5. Poyser MA, Nelson H, Ehrlich RI, et al. Socioeconomic deprivation and asthma prevalence and 5. Poyser MA, Nelson H, Ehrlich RI, et al. Socioeconomic deprivation and asthma prevalence and
severity in young adolescents. Eur Respir J 2002;19(5):892-898. [http://dx.doi.org/10.1183/0903193 6.02.00238402]

6. Williams DR, Herman A, Stein DJ, et al. Twelve-month mental disorders in South Africa: Prevalence, service use and demographic correlates in the population-based South African Stress and Health Study. Psychol Med 2008;38(2):211-220. [http://dx.doi.org/10.1017/S0033291707001420]

7. English RG, Bateman ED, Zwarenstein MF, et al. Development of a South African Integrated Syndromic Respiratory Disease Guideline for Primary Care. Prim Care Respir J 2008;17(3):156-163. [http://dx.doi.org/10.3132/pcrj.2008.00044]

8. Andresen EM, Malmgren JA, Carter WB, Patrick DL. Screening for depression in well older adults: Evaluation of a short form of the CES-D (Center for Epidemiologic Studies Depression Scale). Am J Prev Med 1994;10(2):77-84.

9. Peer N, Steyn K, Lombard C, Gwebushe N, Levitt N. A high burden of hypertension in the urban black population of Cape Town: The Cardiovascular Risk in Black South Africans (CRIBSA) Study. PLoS population of Cape Town: The Cardiovascular Risk in Black South Afnect

Dones PW, Quirk FH, Baveystock CM. The St George's Respiratory Questionnaire. Respir Med 1991;85(Suppl B):25-31. [http://dx.doi.org/10.1016/S0954-6111(06)80166-6]

1991;85(Suppl B):25-31. [http://dx.doi.org/10.1016/S0954-6111(06)80166-6]
1. Executive Summary: Standards of Medical Care in Diabetes - 2013. Diabetes Care 2013;36(Suppl 1):S4-S10. [http://dx.doi.org/10.2337/dc13-S004]

12. Maepe LM, Outhoff K. Hypertension in goldminers. S Afr Med J 2012;102(1):30-33

13. Mendenhall E, Richter LM, Stein A, Norris SA. Psychological and physical co-morbidity among urban South African women. PLoS One 2013;8(10):e78803. [http://dx.doi.org/10.1371/journal. pone.0078803]

14. Barnett K, Mercer SW, Norbury M, et al. Epidemiology of multimorbidity and implications for health care, research, and medical education: A cross-sectional study. Lancet 2012;380(9836):37-43. [http:// dx.doi.org/10.1016/S0140-6736(12)60240-2]

15. Department of Health, Republic of South Africa. Department of Health Annual Report 2011/2012. http://www.health.gov.za/ (accessed 27 June 2014).

16. Department of Health, Republic of South Africa. Primary Care 101. http://www.health.gov.za/docs/ Pepartment of Health, Republic of South Africa. Primary Care 101. http://www
Policies/2013/Low_res_PC_101_Guideline_v2.pdf (accessed 4 November 2014).

Accepted 15 June 2015. 